\title{
Sleeping habits affect access to host by Chagas disease vector Triatoma dimidiata
}

Etienne Waleckx ${ }^{1 *}$, Rafael Pasos-Alquicira ${ }^{1}$, María Jesús Ramírez-Sierra ${ }^{1}$ and Eric Dumonteil ${ }^{1,2}$

\begin{abstract}
Background: Chagas disease, caused by the parasite Trypanosoma cruzi, is mainly transmitted by blood-sucking bugs called triatomines. In the Yucatán Peninsula, Mexico, the main vector of T. cruzi is Triatoma dimidiata. While this species may colonize houses in other regions, it is mostly intrusive in Yucatán: it generally lives in sylvan and peridomestic areas, and frequently enters inside homes, likely attracted by potential vertebrate hosts, without establishing colonies. Bugs collected inside homes have a low nutritional status, suggesting that they cannot efficiently feed inside these houses. We hypothesized that this low nutritional status and limited colonization may be associated, at least in part, with the local practice in Mayan communities to sleep in hammocks instead of beds, as this sleeping habit could be an obstacle for triatomines to easily reach human hosts, particularly for nymphal instars which are unable to fly.

Methods: We used an experimental chamber in which we placed a miniature bed in one side and a miniature hammock on the other side. After placing a mouse enclosed in a small cage on the bed and another one in the hammock as baits, T. dimidiata bugs were released in the chamber and their activity was video recorded during the night.

Results: T. dimidiata adults and nymphs were able to reach the mouse in bed significantly more often than the mouse in hammock (Binomial test, $P<0.0001$ ). Moreover, females reached the mice twice as often as did males. Most of the adult bugs reached the mouse in bed by walking, while they reached the mouse in hammock by flying. Nymphs presented a host-seeking index ten times lower than adult bugs and were also able, on a few occasions (4/132 released bugs), to reach the mouse in hammock.
\end{abstract}

Conclusions: We conclude that sleeping in hammocks, as done in rural Yucatán, makes human hosts less accessible to the bugs. This, combined with other factors (e.g. absence of domestic animals sleeping inside houses), may explain, at least in part, the low nutritional status of bugs collected inside homes and the limited colonization of houses by $T$. dimidiata in the region. Nevertheless, while this sleeping habit limits contact with the bugs, it does not confer complete protection as adult bugs as well as some nymphs were still able to reach the host in hammock in our study.

Keywords: Triatomines, Chagas disease, Intrusion, Feeding, Domiciliation, Yucatán, Mexico

\section{Background}

Chagas disease, caused by the parasite Trypanosoma cruzi, is mainly transmitted to humans and other mammals by blood-sucking insects called triatomines, also known as kissing bugs. This disease is a major public health problem in the Americas, where six to seven million people are estimated to be infected with the parasite [1]. Current estimates suggest that there is a disease burden reaching

\footnotetext{
* Correspondence: etienne.waleckx@correo.uady.mx; etienne.waleckx@ird.fr; etiennewalex@yahoo.fr

'Laboratorio de Parasitología, Centro de Investigaciones Regionales "Dr Hideyo Noguchi", Universidad Autónoma de Yucatán, Mérida, México Full list of author information is available at the end of the article
}

29,385,250 disease-adjusted life-years (DALYs), and health care costs of over $\$ 24,000$ million are attributed to Chagas disease, which exceeds that of other global diseases such as rotavirus infection (\$2000 million) or the cervico-uterine cancer (\$4700 million) $[2,3]$. In Mexico, 31 triatomine species are currently reported, and T. cruzi transmission is reported in most of the territory $[4,5]$. One to two million people are generally estimated to be infected with $T$. cruzi in Mexico, but the more pessimist figures estimate that it could reach 5.5 million people [6, 7]. Despite this, Mexico has only a passive national surveillance program and no 
real national strategy to prevent vector-borne transmission of $T$. cruzi exists.

Triatoma dimidiata is one of the principal insect vectors of T. cruzi. This species as a large geographical distribution, ranging from Ecuador to Southern Mexico [8], and it is the main vector reported in the Yucatán Peninsula in Mexico. While $T$. dimidiata may colonize houses in other regions, particularly in Central America $[9,10]$, this species is mostly intrusive in Yucatán: it lives generally in sylvan and peridomestic areas, and frequently enters inside homes, likely attracted by artificial light and potential vertebrate hosts, without establishing colonies [11-13]. Moreover, bugs collected inside homes have a low nutritional status, suggesting that they cannot efficiently feed inside these houses [14].

The objective of the current study was to test the hypothesis that this low feeding status and limited colonization may be associated, at least in part, with the local practice in Mayan communities to sleep in hammocks instead of beds, as this sleeping habit could be an obstacle for triatomines to easily reach human hosts, particularly for nymphal instars which are unable to fly, thus affecting the accomplishment of their life-cycle.

\section{Methods}

\section{Triatoma dimidiata specimens}

Males, females, and N5 nymphs (fifth-instar nymphs) of uninfected laboratory-reared $T$. dimidiata originating from triatomines collected in the field within the framework of experimental vector control interventions $[15,16]$ in the rural villages of Bokobá $\left(21^{\circ} 00^{\prime} 27^{\prime \prime} \mathrm{N}, 89^{\circ} 10^{\prime} 47^{\prime \prime} \mathrm{W}\right)$, Teya $\left(21^{\circ} 02^{\prime} 55^{\prime \prime} \mathrm{N}, 89^{\circ} 04^{\prime} 25^{\prime \prime} \mathrm{W}\right)$ and Sudzal $\left(20^{\circ} 52^{\prime} 19^{\prime \prime} \mathrm{N}\right.$, $\left.88^{\circ} 59^{\prime} 20^{\prime \prime} \mathrm{W}\right)$, were used. The bugs, maintained by feeding every 2-3 weeks on pigeons, were starved for 10-15 days before being used in the experiments.

\section{Triatoma dimidiata host-seeking behaviour assay}

To observe the host-seeking behaviour of $T$. dimidiata, we used an experimental chamber consisting of a rectangular arena $(0.5 \times 1 \times 0.5 \mathrm{~m})$ made with a wooden floor, plastic insect screen walls, and a glass ceiling, in which we placed a miniature bed in one side and a miniature hammock on the other side (Fig. 1). After placing a mouse enclosed in a cage on the bed and another one in the hammock, we placed a small cardboard box containing $T$. dimidiata bugs, and serving as a refuge, in the middle of the chamber at dusk. Bugs could then exit the cardboard refuge and forage freely within the chamber until the next morning. The activity of the bugs was video recorded $(7 \mathrm{pm}-7 \mathrm{am})$ to measure the number and time of accesses to both mice, and how each access occurred (i.e. flying or walking) (Fig. 1). This assay was repeated for 18 nights (five nights with ten males, five nights with ten females, four nights with eight N5 nymphs, and four nights with 25 N5 nymphs). The positions of the bed and the hammock were switched between each experiment to avoid any bias.

\section{Data analysis}

The host-seeking index was defined as the ratio between the number of accesses to both mice and the total number of bugs released. The proportions of bugs which reached the mouse in bed $v s$ hammock were compared by using binomial tests and the association between the sleeping location of the mice (bed $v s$ hammock) and how these were reached by adult bugs (walking $v s$ flying) was tested using the Chi-square $\left(\chi^{2}\right)$ test. In all cases, $P<0.05$ was considered statistically significant.

\section{Results}

\section{Activity of Triatoma dimidiata bugs}

In total, 232 bugs, including 50 males, 50 females, and 132 N5 nymphs were released over the 18 nights of the experiment. Mice were reached 123 times, giving a global host-seeking index of 0.53 (123/232, Table 1). Females reached the mice twice as often as did males (host-seeking index, 1.44 and 0.68 , respectively). Moreover, the N5 nymph host-seeking index (0.13) was almost 10 times lower than the adult index (1.06, Table 1). Finally, we observed an increase of the number of accesses to both mice as the night progressed (Fig. 2). Accesses to mice were observed for all but one ( 9 to $10 \mathrm{pm}$ ) 1 -h time intervals among the 18 nights of the experiment, ranging from 1 access between 7 and $8 \mathrm{pm}$ to 21 accesses between 6 and 7 am.

\section{Bed vs hammock}

As observed in Fig. 3, released bugs reached the mouse in bed two to three times more frequently than the mouse in hammock. Of a total of 123 recorded accesses to hosts, $85(69.1 \%)$ were done to the mouse in bed. The difference between the access to mice in bed $v s$ hammock was significant for all bugs taken together, as well as for each stage and sex separately (Binomial tests, $P<0.05$ in all cases). The effect tended to be more pronounced for N5 nymphs (access to bed: $76.5 \%$ vs access to hammock: $23.5 \%$ ) than for adult bugs (67.9 vs $32.1 \%)$, but this tendency did not reach significance $\left(\chi^{2}=0.5012, d f=1, P=0.479\right)$. Interestingly, nymphs were also able, on a few occasions (4/132 released bugs), to reach the mouse in hammock by walking along the arms of the hammock.

\section{Walking vs flying}

More than $93 \%(67 / 72)$ of the recorded accesses of adult bugs to the mouse in bed were by walking, while the mouse in hammock was reached by flying adults in $88 \%(30 / 34)$ of cases (Fig. 4). There was a significant association between the sleeping location of the mice (bed 


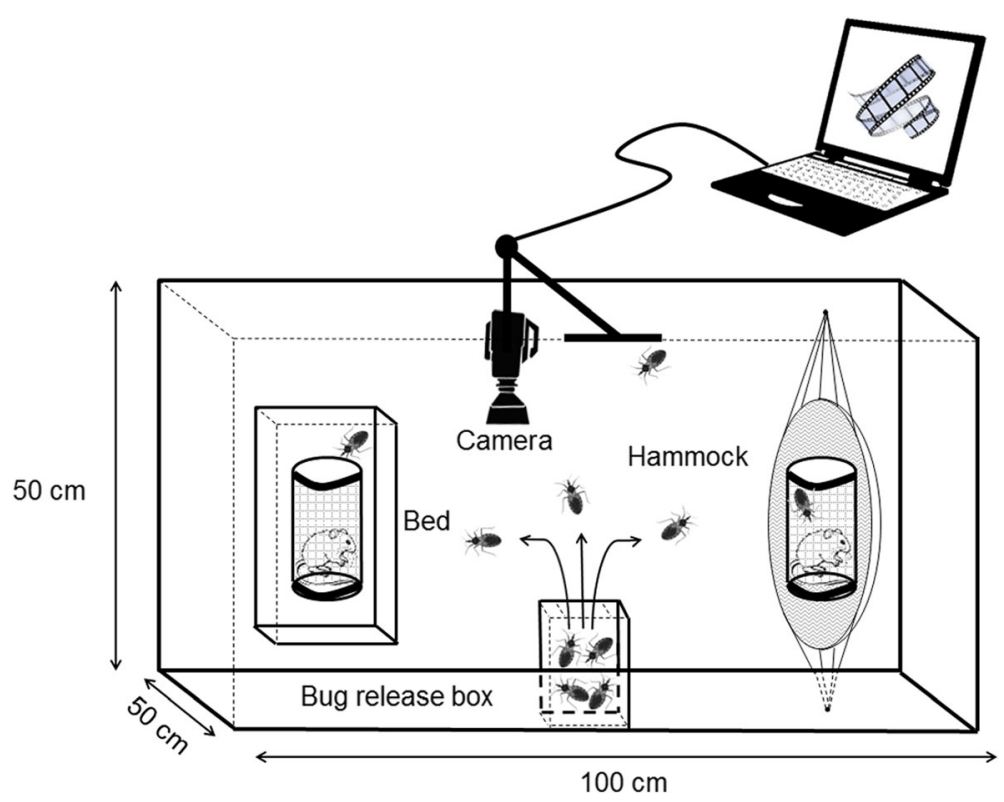

Fig. 1 Experimental system. Upper view

$v s$ hammock) and how they were reached by adult bugs (walking $v s$ flying) $\left(\chi^{2}=69.04, d f=1, P<0.0001\right)$.

\section{Discussion}

The level of domiciliation/intrusion of triatomine species is a major determinant of their vectorial capacity and has important implications for the design of effective vector control interventions [18]. In the Yucatán Peninsula, Mexico, $T$. dimidiata is responsible for a seroprevalence of T. cruzi infection in humans of up to $4-5 \%$ in rural areas [19]. In this region, the intrusive behaviour of $T$. dimidiata, characterized by an infestation of human dwellings by sylvatic and peridomestic adult bugs on a seasonal basis without establishment of colonies, is well documented [11, 12, 20-23]. This seasonal intrusion into human dwellings makes control efforts challenging in Yucatán. For instance, modelling studies have suggested that vector control interventions based on insecticide spraying would not be suitable, particularly because of the necessity to spray insecticide yearly during a reduced

Table 1 Host-seeking index of the bugs by sex and stage

\begin{tabular}{lllc}
\hline & $\begin{array}{l}\text { Total no. of bugs } \\
\text { released }\end{array}$ & $\begin{array}{l}\text { No. of times bugs accessed } \\
\text { to mice in bed/hammock }\end{array}$ & $\begin{array}{l}\text { Host-seeking } \\
\text { index }^{\mathrm{a}}\end{array}$ \\
\hline Males & 50 & 34 & 0.68 \\
Females & 50 & 72 & 1.44 \\
N5 & 132 & 17 & 0.13 \\
nymphs & & & \\
Total & 232 & 123 & 0.53
\end{tabular}

The host-seeking index was defined as the ratio between the number of times bugs accessed to mice in bed/hammock and the total number of bugs released

Abbreviation: N5 fifth-instar period of time in the year, almost operationally impossible [24]. Alternative control intervention strategies, based on the Ecohealth principles, have recently been implemented at different pilot scales $[15,16,25]$ and are currently giving promising results (Waleckx et al., unpublished data). While $T$. dimidiata generally does not establish colonies inside human dwellings in the Yucatán Peninsula, in other parts of its geographical distribution, such as in Guatemala, populations are well domiciliated, as evidenced by bug collections throughout the country showing high infestation and colonization indexes $[10,26]$.

The limited colonization of human dwellings in the Yucatán Peninsula has been proposed to be related to a low fecundity and high mortality resulting from poor feeding of bugs inside houses [14]. This may be explained by the fact that domestic animals are generally kept close to but outside dwellings in the region [12]. Nevertheless, other factors may also be involved and here, we particularly investigated the role of the local practice to sleep in hammocks instead of beds.

In our study, we first observed that $T$. dimidiata females gained access to mice in bed/hammock twice more than did males. This observation may be explained by a higher voracity of females, as reported by Zeledon et al. [27]. In their study, Zeledon et al. did not compare the voracity of nymphal instars with that of adults, but our results suggest that N5 nymphs are less voracious as they acceded to the mice 10 times less than adult bugs.

Foraging of triatomine bugs for hosts is believed to occur mostly early in the night, while the search for refuges occurs later at night, supposedly after feeding [28]. Here, we observed that host-seeking increased as 


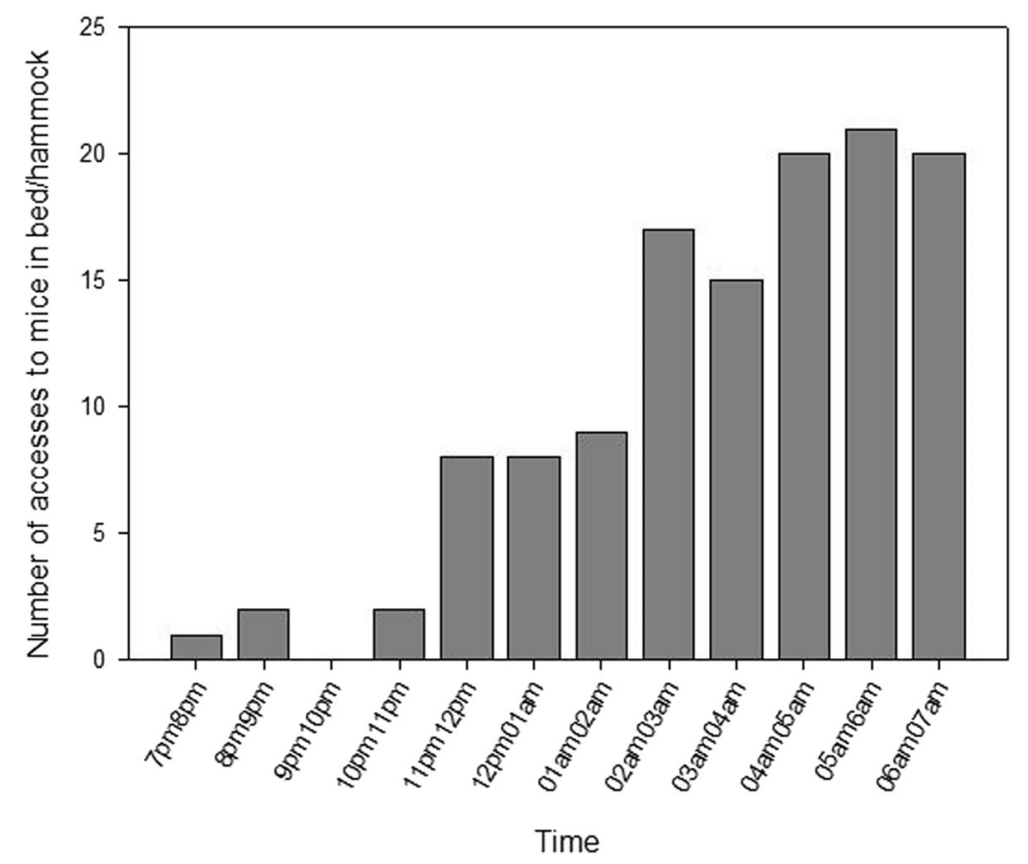

Fig. 2 Number of accesses to mice in bed/hammock as a function of time

the night progressed. A similar pattern has already been reported for $T$. dimidiata under experimental conditions $[13,29]$. It is unclear if this is specific to this species, or if it is due to the different experimental systems, in which the bugs were not able to feed (e.g. in the current experiment, mice were placed inside small cages protecting them from the bites). Bugs may thus keep foraging actively for a much longer period of time in an attempt to reach the detected host. Nevertheless, bugs may also have difficulty in finding available hosts in natural conditions and may present an activity pattern similar to the one observed here. Alternative experimental

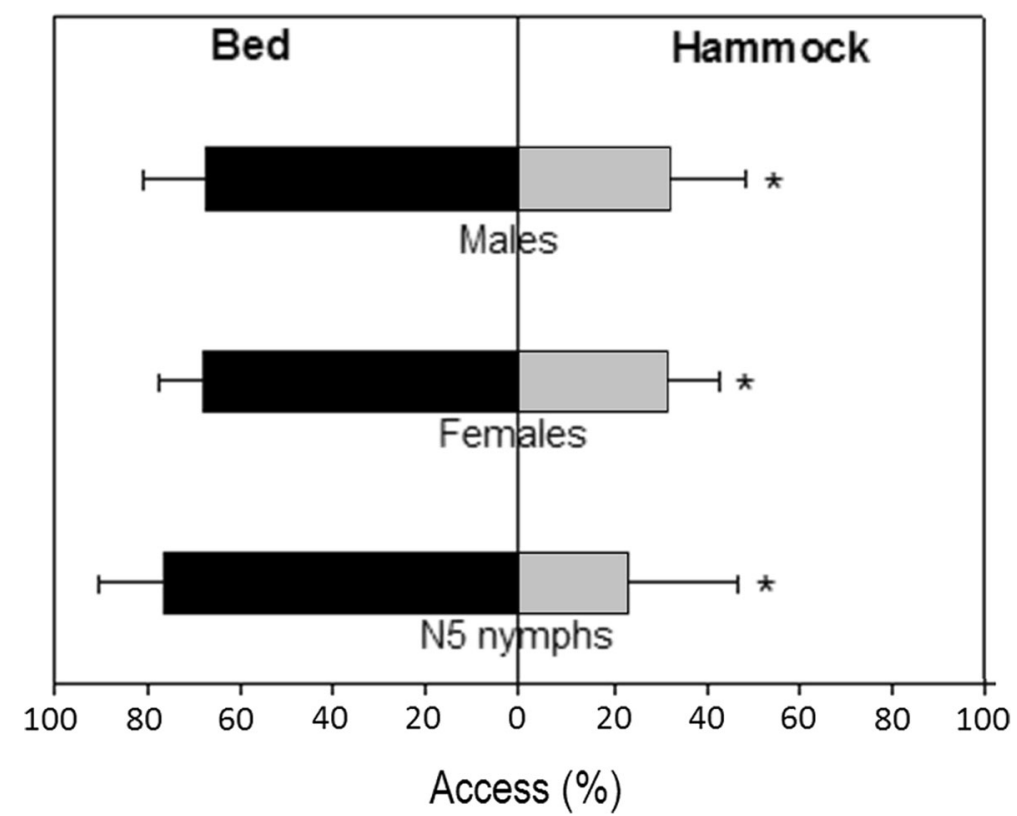

Fig. 3 Percentage of access to mouse in bed vs hammock. Error bars represent the upper limit of the $95 \%$ confidence interval, according to Newcombe [17], without correction for continuity. *indicates a significant difference between bed and hammock (Binomial tests; males: $P=0.029$; females: $P=0.0015$; N5 nymphs: $P=0.0245$ ) 


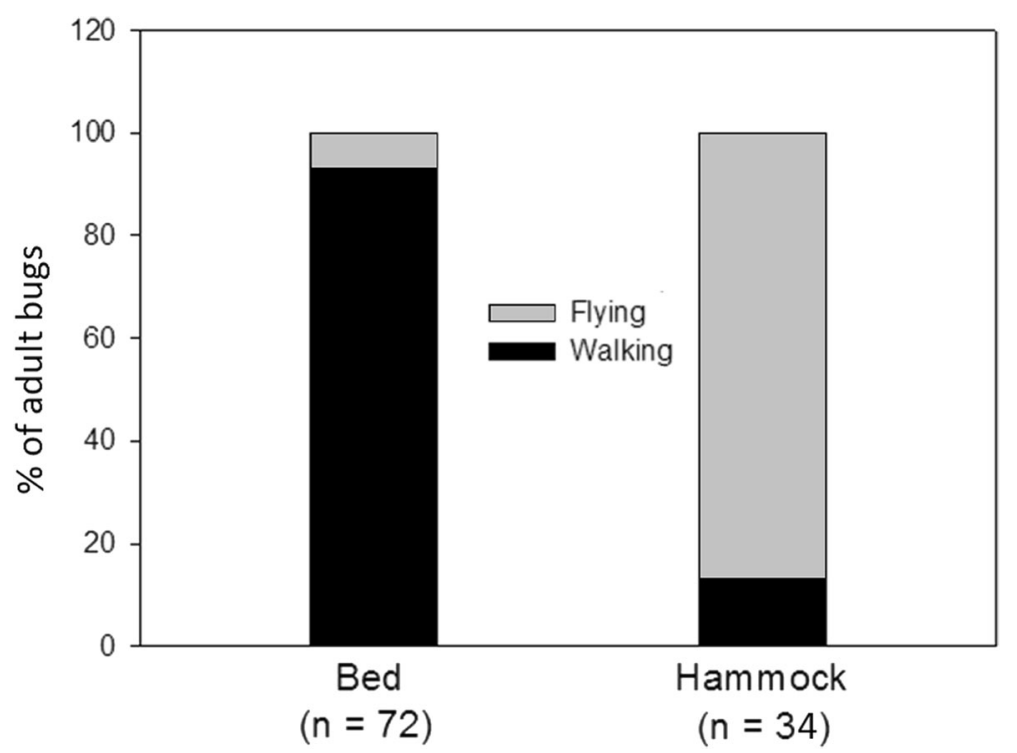

Fig. 4 Proportion of adult bugs which walked/flew to the bed/hammock ( $n$, total number of adult bugs which reached the mice in bed/hammock)

systems may be developed in future studies to further explore the host-seeking behaviour of $T$. dimidiata.

Importantly, we found in our study that bugs were able to gain significantly more access to the mouse in bed compared to the mouse in hammock, suggesting that the latter makes the host less accessible to the bugs. This "hammock effect" tended to be higher for N5 nymphs, which are unable to fly, and a significant association between the location of the mice and the way they were reached (almost $80 \%$ of accesses to the host in hammock were done by flying bugs) was found. The observed hammock effect might even be more pronounced for younger nymphal instars, which are believed to have a reduced activity compared to older nymphal instars and adult bugs. If confirmed, the latter hypothesis is interesting because it means that even if a female releases eggs in a human dwelling in an attempt to colonize, young nymphs might have difficulty feeding, leading to their death, and thus preventing successful colonization of human dwellings. In this sense, a very low survival of nymphal instars of $T$. dimidiata was previously predicted by mathematical models fitted to $T$. dimidiata demographic data in the Yucatán Peninsula [21].

\section{Conclusions}

The results of our study suggest that sleeping in hammocks, as is common practice in rural Yucatán, makes human hosts less accessible to triatomine bugs. This, combined with other factors (e.g. absence of domestic animals sleeping inside houses), may explain at least in part, the low nutritional status of bugs collected inside houses and the subsequent limited colonization of homes by $T$. dimidiata in the region. Nevertheless, while this sleeping habit limits contacts with the bugs, it does not confer complete protection as adult bugs as well as N5 nymphs were still able to reach the host sleeping in hammock in our study. Confirmation of these findings in the field would be interesting but may be difficult to perform because of ethical issues.

In the Yucatán Peninsula, Mexico, sleeping in hammock is an important cultural practice, primarily because hammocks are more comfortable than beds in this very warm region as they allow a best air flush. While Mayan communities do not associate this practice with vector protection [12, 30], it could be promoted as part of Ecohealth vector control strategies. Indeed, it could help prevent the colonization of human dwellings by $T$. dimidiata as well as help limit the exposition of human populations to triatomine bites and Chagas disease transmission.

\section{Abbreviations}

DALYs: Disease-adjusted life-years; N5: Fifth-instar nymph

\section{Acknowledgements}

The authors would like to thank Silvia Margarita Pérez Carrillo for her help in maintaining the $T$. dimidiata colony from which the bugs used in the study are from.

\section{Funding}

This investigation received financial support from the UNDP/World Bank/WHO Special Program for Research and Training in Tropical Diseases (TDR)/ International Development Research Center (IDRC), Project \#A90276.

\section{Availability of data and material}

The datasets supporting the conclusions of this article are included within the article.

\section{Authors' contributions}

Designed the study (EW, RPA, MJRS, ED), performed the experiments (RPA), computed data (EW, RPA), analyzed data (EW, RPA, ED), wrote the manuscript (EW, ED). All authors read and approved the final version of the manuscript. 


\section{Competing interests}

The authors declare that they have no competing interests.

\section{Consent for publication}

Not applicable.

\section{Ethics approval and consent to participate}

This study was approved through the Bioethics committee of CIR-UADY (Registration number CBI-CIR-11-016). In the cages in which mice were enclosed for each night of the experiment, a small amount of wood shavings and food was added to limit their discomfort and distress. Moreover, appropriate biosecurity techniques and individual protection equipment were used in all procedures for the handling of the biological samples.

\section{Author details}

'Laboratorio de Parasitología, Centro de Investigaciones Regionales "Dr Hideyo Noguchi", Universidad Autónoma de Yucatán, Mérida, México. ${ }^{2}$ Department of Tropical Medicine, Tulane University, School of Public Health and Tropical Medicine, New Orleans, LA, USA.

Received: 4 August 2016 Accepted: 19 October 2016

Published online: 03 November 2016

\section{References}

1. World Health Organization. Chagas disease (American trypanosomiasis), Fact sheet $N^{\circ}$ o. 340. 2016. http://www.who.int/mediacentre/factsheets/fs340/en/. Accessed 24 Oct 2016

2. Lee BY, Bacon KM, Bottazzi ME, Hotez PJ. Global economic burden of Chagas disease: a computational simulation model. Lancet Infect Dis. 2013;13(4):342-8.

3. Naghavi M, Wang HD, Lozano R, Davis A, Liang XF, Zhou MG, et al. Global, regional, and national age-sex specific all-cause and cause-specific mortality for 240 causes of death, 1990-2013: a systematic analysis for the Global Burden of Disease Study 2013. Lancet. 2015;385(9963):117-71.

4. Secretaría de Salud de México. Informes de morbilidad. 2016. http://www. epidemiologia.salud.gob.mx/dgae/boletin/intd_boletin.html. Accessed 24 Oct 2016.

5. Ramsey JM, Peterson AT, Carmona-Castro O, Moo-Llanes DA, Nakazawa $Y$, Butrick $M$, et al. Atlas of Mexican Triatominae (Reduviidae: Hemiptera) and vector transmission of Chagas disease. Mem Inst Oswaldo Cruz. 2015;110(3):339-52.

6. Carabarin-Lima A, Gonzalez-Vazquez MC, Rodriguez-Morales O, BaylonPacheco L, Rosales-Encina JL, Reyes-Lopez PA, et al. Chagas disease (American trypanosomiasis) in Mexico: an update. Acta Trop. 2013;127(2):126-35.

7. Cruz-Reyes A, Pickering-Lopez JM. Chagas disease in Mexico: an analysis of geographical distribution during the past 76 years - a review. Mem Inst Oswaldo Cruz. 2006;101(4):345-54.

8. Dorn PL, Monroy C, Curtis A. Triatoma dimidiata (Latreille, 1811): a review of its diversity across its geographic range and the relationship among populations. Infect Genet Evol. 2007;7(2):343-52.

9. Monroy C, Rodas A, Mejia M, Rosales R, Tabaru Y. Epidemiology of Chagas disease in Guatemala: Infection infection rate of Triatoma dimidiata, Triatoma nitida and Rhodnius prolixus (Hemiptera, Reduviidae) with Trypanosoma cruzi and Trypanosoma rangeli (Kinetoplastida, Trypanosomatidae). Mem Inst Oswaldo Cruz. 2003;98(3):305-10.

10. Monroy MC, Bustamante DM, Rodas AG, Enriquez ME, Rosales RG. Habitats, dispersion and invasion of sylvatic Triatoma dimidiata (Hemiptera : Reduviidae : Triatominae) in Peten, Guatemala. J Med Entomol. 2003;40(6):800-6.

11. Dumonteil E, Gourbiere S, Barrera-Perez M, Rodriguez-Felix E, Ruiz-Pina H, Banos-Lopez O, et al. Geographic distribution of Triatoma dimidiata and transmission dynamics of Trypanosoma cruzi in the Yucatán Peninsula of Mexico. Am J Trop Med Hyg. 2002;67(2):176-83.

12. Dumonteil E, Nouvellet P, Rosecrans K, Ramirez-Sierra MJ, Gamboa-Leon R, Cruz-Chan V, et al. Eco-bio-social determinants for house infestation by non-domiciliated Triatoma dimidiata in the Yucatán Peninsula, Mexico. PLoS Negl Trop Dis. 2013;7(9), e2466.

13. Pacheco-Tucuch FS, Ramirez-Sierra MJ, Gourbiere S, Dumonteil E. Public street lights increase house infestation by the Chagas disease vector Triatoma dimidiata. PLoS One. 2012;7(4), e36207.
14. Payet V, Ramirez-Sierra MJ, Rabinovich J, Menu F, Dumonteil E. Variations in sex ratio, feeding, and fecundity of Triatoma dimidiata (Hemiptera: Reduviidae) among habitats in the Yucatán Peninsula, Mexico. Vector Borne Zoonotic Dis. 2009:9(3):243-51.

15. Ferral J, Chavez-Nunez L, Euan-Garcia M, Ramirez-Sierra MJ, Najera-Vazquez MR, Dumonteil E. Comparative field trial of alternative vector control strategies for non-domiciliated Triatoma dimidiata. Am J Trop Med Hyg. 2010;82(1):60-6.

16. Waleckx E, Camara-Mejia J, Ramirez-Sierra MJ, Cruz-Chan V, Rosado-Vallado M, Vazquez-Narvaez $S$, et al. An innovative ecohealth intervention for Chagas disease vector control in Yucatán, Mexico. Trans R Soc Trop Med Hyg. 2015;109(2):143-9.

17. Newcombe RG. Two-sided confidence intervals for the single proportion: comparison of seven methods. Stat Med. 1998;17(8):857-72.

18. Waleckx E, Gourbiere S, Dumonteil E. Intrusive versus domiciliated triatomines and the challenge of adapting vector control practices against Chagas disease. Mem Inst Oswaldo Cruz. 2015;110(3):324-38.

19. Gamboa-Leon R, Ramirez-Gonzalez C, Pacheco-Tucuch FS, O'Shea M, Rosecrans K, Pippitt J, et al. Seroprevalence of Trypanosoma cruzi among mothers and children in rural Mayan communities and associated reproductive outcomes. Am J Trop Med Hyg. 2014;91(2):348-53.

20. Dumonteil E, Ramirez-Sierra MJ, Ferral J, Euan-Garcia M, Chavez-Nunez L. Usefulness of community participation for the fine temporal monitoring of house infestation by non-domiciliated triatomines. J Parasitol. 2009;95(2):469-71.

21. Gourbiere S, Dumonteil E, Rabinovich JE, Minkoue R, Menu F. Demographic and dispersal constraints for domestic infestation by non-domiciliated Chagas disease vectors in the Yucatán Peninsula, Mexico. Am J Trop Med Hyg. 2008;78(1):133-9.

22. Barbu C, Dumonteil E, Gourbiere S. Characterization of the dispersal of nondomiciliated Triatoma dimidiata through the selection of spatially explicit models. PLoS Negl Trop Dis. 2010;4(8), e777.

23. Dumonteil E, Tripet F, Ramirez-Sierra MJ, Payet V, Lanzaro G, Menu F. Assessment of Triatoma dimidiata dispersal in the Yucatán Peninsula of Mexico by morphometry and microsatellite markers. Am J Trop Med Hyg. 2007;76(5):930-7.

24. Barbu C, Dumonteil E, Gourbiere S. Optimization of control strategies for non-domiciliated Triatoma dimidiata, Chagas disease vector in the Yucatán Peninsula, Mexico. PLoS Negl Trop Dis. 2009;3(4), e416.

25. Charron DF. Ecohealth Research in Practice. Ottawa: IDRC; 2012.

26. Nakagawa J, Juarez J, Nakatsuji K, Akiyama T, Hernandez G, Macal R, et al. Geographical characterization of the triatomine infestations in north-central Guatemala. Ann Trop Med Parasitol. 2005;99(3):307-15.

27. Zeledon R, Guardia VM, Zuñiga A, Swartzwelder JC. Biology and ethology of Triatoma dimidiata (Latreille, 1811) I. Life cycle, amount of blood ingested, resistance to starvation, and size of adults. J Med Entomol. 1970;7(3):313-9.

28. Lorenzo MG, Lazzari CR. Activity pattern in relation to refuge exploitation and feeding in Triatoma infestans (Hemiptera : Reduviidae). Acta Trop. 1998;70(2):163-70

29. Ramirez-Sierra MJ, Dumonteil E. Infection rate by Trypanosoma cruzi and biased vertebrate host selection in the Triatoma dimidiata (Hemiptera: Reduvidae) species complex. J Med Entomol. 2016;53(1):20-5.

30. Rosecrans K, Cruz-Martin G, King A, Dumonteil E. Opportunities for improved Chagas disease vector control based on knowledge, attitudes and practices of communities in the Yucatán Peninsula, Mexico. Plos Negl Trop Dis. 2014;8(3):e2763.

\section{Submit your next manuscript to BioMed Central and we will help you at every step:}

- We accept pre-submission inquiries

- Our selector tool helps you to find the most relevant journal

- We provide round the clock customer support

- Convenient online submission

- Thorough peer review

- Inclusion in PubMed and all major indexing services

- Maximum visibility for your research

Submit your manuscript at www.biomedcentral.com/submit 